\title{
Analytic and Nonlinear Prognostic for Vehicle Suspension Systems
}

\author{
${ }^{1}$ Abdo Abou Jaoude and ${ }^{2}$ Khaled El-Tawil \\ ${ }^{1}$ Paul Cezanne University Aix-Marseille, France and the Lebanese University, (EDST) Hadath, Lebanon \\ ${ }^{2}$ Faculty of Engineering and EDST, Lebanese University, Hadath, Lebanon
}

Received 2012-09-17, Revised 2012-12-27; Accepted 2013-04-23

\begin{abstract}
Predicting Remaining Useful Lifetime (RUL) of industrial systems becomes currently an important aim for industrialists knowing that the expensive failure can occur suddenly. As the classical strategies of maintenance are not efficient and practical because they neglect the evolving product state and environment, the recent prognostic approaches try to fill this gap. This approach shows to be important in ensuring high availability in minimum costs for industrial systems, like in aerospace, defense, petro-chemistry and automobiles. An analytic prognostic methodology based on existing damage laws in fracture mechanics, such as Paris' and Miner's laws, is recently developed for determining the system RUL. Damages have been assumed to be accumulated linearly, since we have considered the widely used linear Miner's law. In this study, the nonlinear case in damage accumulation is explored to take into account the complex behavior of some materials subject to fatigue effects. It is useful especially when the nature of applied constraints and influent environment contribute to accentuate this nonlinearity. Our damage model is based on the accumulation of a damage measurement $\mathrm{D}(\mathrm{N})$ after each loading cycle $\mathrm{N}$. In automobile industry, the prognostic assessment of the suspension component by this developed nonlinear approach shows its importance for the same earlier reasons.
\end{abstract}

Keywords: Analytic Laws, Degradation, Fatigue, Miner's Law, Paris' Law, Nonlinear Cumulative Damage, Prognostic

\section{INTRODUCTION}

It is well known that each system passes by three phases during its whole life. The last phase represents the degradation period of the system and which leads to failure by progressive deterioration. It is important for industrialists to predict, at each instant, the remaining lifetime in order to prevent expensive and unexpected failure. Early detection also helps in avoiding catastrophic failures. Adopting preventive systematic maintenance to increase the system availability proves to be an expensive strategy due to the frequent replacement of generally expensive accessories (Inman et al., 2005).

Moreover, this strategy is not efficient because most of equipments failures are not related only to the number of hours of functioning. The prognostic (Vachtsevanos et al.,
2006) is a methodology that aims to predict the Remaining Useful Lifetime (RUL) of a system in service. RUL can be expressed in hours of functioning, in Kilometers run or in cycles. Lee (2004) defines prognostics as the ability to "predict and prevent" possible fault or system degradation before failures occur. Prognosis has been defined by (Lewis and Edwards, 1997) as "prediction of when a failure may occur" i.e., a mean to calculate remaining useful life of an asset. If we can effectively predict the condition of machines and systems, maintenance actions can be taken ahead of time. In order to make a good and reliable prognosis it must have good and reliable diagnosis.

An earlier prognostic work (Peysson, 2009) on vehicle suspension system used an analytical model based on degradation laws like Paris' law for fatigue

Corresponding Author: Abdo Abou Jaoude, Paul
(EDST) Hadath, Lebanon 
degradation and Miner's law for linear cumulative fatigue damage. A degradation indicator $\mathrm{D}$ was taken to describe the evolution from an initial micro-damage till the total system failure.

Until now, damages have been assumed to accumulate linearly (Miner's law) even though it is unlikely to be the case of brittle material. The present paper will explore the nonlinear side of cumulative damage to take into account the nature of the applied constraints and influent environment that can accentuate the nonlinear aspect related to some materials behavior subject to fatigue effects.

\subsection{Nonlinear-Damage-based Prognostic: State of the Art}

Various approaches to prognostics have been developed that range in fidelity from simple historical failure rate models to high-fidelity physics-based models (Byington et al., 2002). The required information (depending on the type of prognostics approach) include: engineering model and data, failure history, past operating conditions, current conditions, identified fault patterns, transitional failure trajectories, maintenance history, system degradation and failure modes.

A number of different methods have been applied to study prognosis of degraded components. In general, prognostics approaches can be classified into three primary categories: (1) model driven, (2) data driven and (3) probability based prognostic techniques.

The main advantage of model based approaches is their ability to incorporate physical understanding of the monitored system (Luo et al., 2003). Moreover, if the understanding of the system degradation improves, the model can be adapted to increase its accuracy and to address subtle performance problems. Consequently, they can significantly outperform data-driven approaches. But, this closed relation with a mathematical model may also be a strong weakness: It can be difficult, even impossible to catch the system's behavior. Furthermore, some authors think that the monitoring and prognostic tools must evolve as the system does.

An earlier proposed procedure (Abou Jaoude et al., 2010) belongs to the first prognostic approach and is based on a physical model leading to a degradation indicator. It is focused on developing and implementing effective diagnostic and prognostic technologies with the ability to detect faults in the early stages of degradation. Early detection and analysis may lead to better prediction and end of life estimates by tracking and modeling the degradation process. The idea was to use these estimates to make accurate and precise prediction of the time to failure of components. The case of fatigue degradation chosen is mathematically formulated by analytic laws such as Paris and Miner laws. The last law is a linear cumulative damage model.

Past research has shown there is a nonlinear interaction effect between High Cycle Fatigue (HCF) and Low Cycle Fatigue (LCF) in many engineering materials. This effect has been observed within uniaxial loadings, but is often more pronounced under multiaxial loading, particularly when the loading is nonproportional. An example here is the development of fatigue damage assessment methods for turbine engine materials combining the LCF and HCF cycles.

The nonlinear interaction effect precludes the use of the most common technique for damage accumulation, the Palmgren-Miner linear damage rule. A thorough review of nonlinear cumulative damage methodologies (Goodin et al., 2007) shows that these techniques have included simple extensions of the linear damage rule to include nonlinear terms. Several nonlinear methods exist, including endurance-limit modification techniques, fracture-mechanics based approaches, continuumdamage and life-curve approaches. Traditional methods of damage summation have been shown to provide an inaccurate life prediction when multiple load levels are simultaneously considered. This is due to the effect that one load level has on the other (s).

In the present study, the effect of HCF loading has had a more detrimental effect when coupled with the LCF loadings than predicted by a linear summation rule. Nonlinear damage accumulation theories can account for this influence and have shown an improvement in prediction. The stress levels were chosen to correspond to levels previously tested to failure, resulting in fatigue lives ranging from approximately $10^{5}$ to $10^{7}$ cycles. A nonlinear damage summation is required to properly define the fatigue process since the linear summation of damage (Miner's sum) is often not adequate to predict the service life of a component when subjected to variable-amplitude loadings.

\subsection{Linear Damage Rule}

The most common method of summing damage for a loading spectrum is the Miner's rule (Miner, 1945). It is readily understood and easy to implement and is, therefore, the foundation for many of the other proposed cumulative damage theories. Ideally, the summation of life ratios would equal one at failure. However, past experiments have yielded a range of ratios from 0.7 to 2.2 for uniaxial loadings, resulting in failure predictions erring just slightly on the side of non-conservative to 
more than the double for a conservative prediction (Shigley and Mischke, 1989). For the biaxial loadings, a Miner's summation of 0.19 was found indicating extremely non-conservative results.

The largest drawback of the linear damage rule is its inability to account for the order of loading. That is, the resulting failure prediction is independent of the load interaction effects that have been observed between high-cycle and low-cycle loadings. It is this shortcoming that has prompted the development of several nonlinear cumulative damage theories.

\subsection{Double Linear Damage Rule (DLDR)}

The current form of the DLDR was proposed in 1966 (Manson et al., 1967). Instead of a single straight line, a set of two straight lines that converged at a common "Kneepoint" would be used (Fig. 1). It helps differentiate between the damage caused by the LCF and HCF for multi-level loadings. It replaces the continuous damage curve by two straight lines. Each linear phase can be analyzed by Miner's linear damage rule. The difficulty in DLDR rule is in establishing the location of the transitory point between the two loading phases Equation 1:

$\left.\left.\frac{\mathrm{n}_{1}}{\mathrm{~N}_{1}}\right]_{\text {knee }}=0.35\left[\frac{\mathrm{N}_{1}}{\mathrm{~N}_{2}}\right]^{\alpha} \frac{\mathrm{n}_{2}}{\mathrm{~N}_{2}}\right]_{\text {knee }}=0.65\left[\frac{\mathrm{N}_{1}}{\mathrm{~N}_{2}}\right]^{\alpha}$

Where:

$\mathrm{n}_{1}$ and $\mathrm{n}_{2}=$ The number of applied cycles at a load levels 1 and 2

$\mathrm{N}_{1}$ and $\mathrm{N}_{2}=$ The failure lives for load levels 1 and 2

$\alpha=$ The material parameter

\subsection{Damage Curve Approach (DCA)}

To better describe fatigue failure using nonlinear damage, instead of a straight line, a single continuous curve reflects more accurately the influence of the loading (Fig. 2). For HCF loading a significant number of cycles had to be applied before enough damage could accumulate to cause a reduction in life. Once the appropriate number of cycles had been applied, the damage continued to accumulate at an ever-increasing rate and failure was soon to follow. For LCF loadings, this behavior was less pronounced. A workable equation based on early crack growth theories was provided Equation 2(Manson and Halford, 1981):

$$
\mathrm{D}=\left(\frac{\mathrm{n}}{\mathrm{N}_{\mathrm{f}}}\right)^{\left(\frac{\mathrm{N}_{\mathrm{f}}}{\mathrm{N}_{\mathrm{ref}}}\right)^{\alpha}}
$$

Where:

$\mathrm{N}_{\mathrm{f}}=$ Number of cycles to failure

$\mathrm{N}_{\text {ref }}=$ Reference life taken as 1

The primary advantage in employing the DCA model lies in its ability to create identical damage curves for different life references.

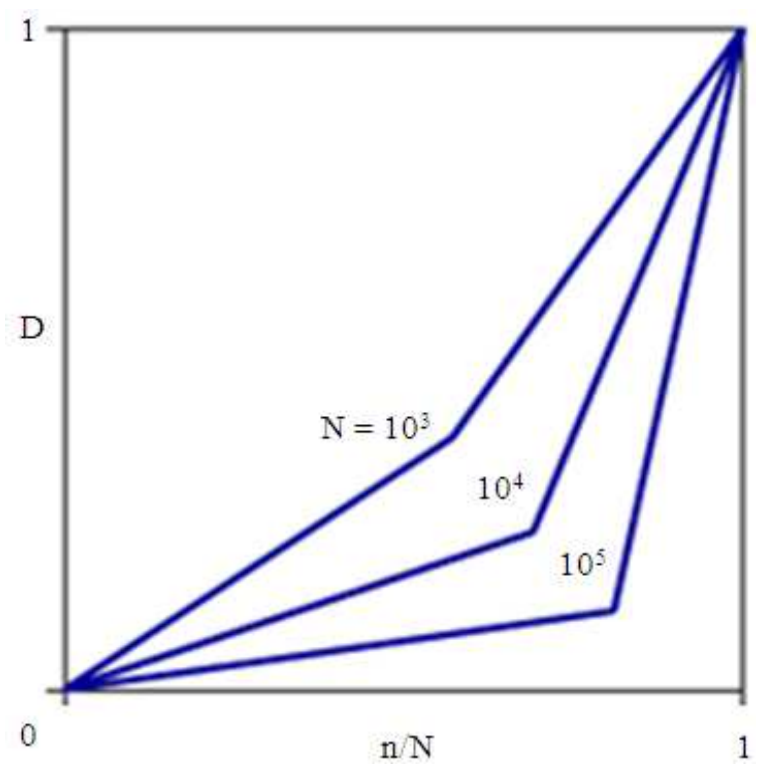

Fig. 1. DLDR rule

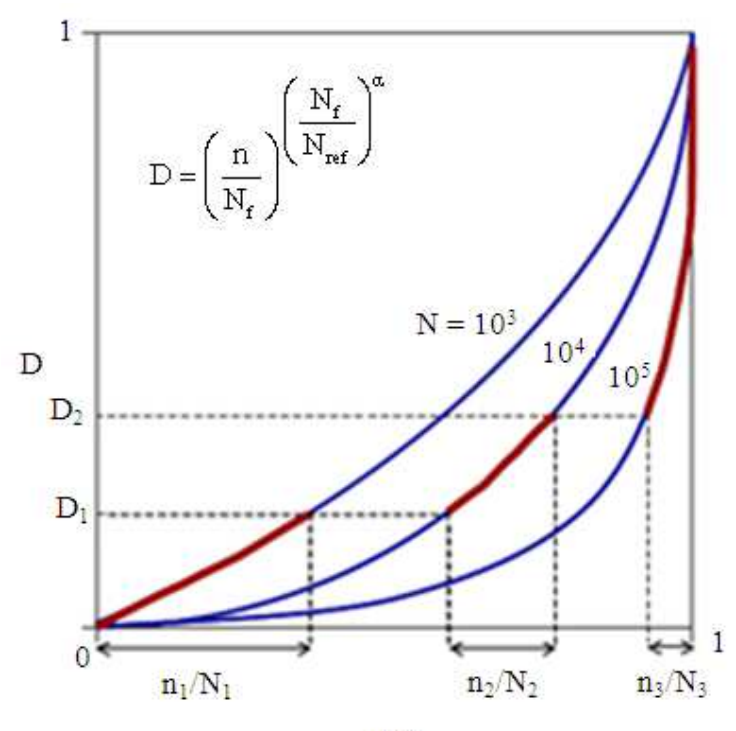

$\mathrm{n} / \mathrm{N}$

Fig. 2. DCA approach 
The linear damage line becomes the reference life that is used to establish the material constant in the Equation 2 above and other damage curves shift values accordingly.

\subsection{Double Damage Curve Approach (DDCA)}

Although the DCA shows large potential in accurately predicting failure in multi-level loading, there is one serious drawback when considering high-low loading. It can be seen upon examination that with the application of just a few high-amplitude cycles, there is a rapid decrease in remaining life at the low-amplitude load level. This result is from a lack of the low-range data needed to adjust the shape of the curve during the models conception. To improve the model, Manson and Halford (1986) included a linear term to shift the curves away from the x-axis. The difficulty would be to allow this new term to have a significant influence at low life ratios but negligible effect at higher ratios. The resulting Double Damage Curve Approach (DDCA) (Fig. 3) closely approximated the DLDR in the lower-life regime and the DCA in the higher-life regime, where each model performed best. The equation for the DDCA is shown below Equation 3:

$$
\mathrm{D}=\left(\frac{\mathrm{n}}{\mathrm{N}}\right) \cdot\left\{\mathrm{q}_{1}^{\gamma}+\left[1-\mathrm{q}_{1}^{\gamma}\right] \cdot\left[\frac{\mathrm{n}}{\mathrm{N}}\right]^{\gamma\left(\mathrm{q}_{2}-1\right)}\right\}^{\frac{1}{\gamma}}
$$

Where:

$$
\mathrm{D}=\text { Damage accumulated }
$$

$\mathrm{n}=$ Number of applied cycles at a given load level

$\mathrm{N}=$ Number of cycles required to fail at the load level of $n$ :

$$
\mathrm{q}_{1}=\frac{0.35\left(\frac{\mathrm{N}_{\text {ref }}}{\mathrm{N}}\right)^{\alpha}}{1-0.65\left(\frac{\mathrm{N}_{\mathrm{ref}}}{\mathrm{N}}\right)^{\alpha}} \quad \text { and } \quad \mathrm{q}_{2}=\left(\frac{\mathrm{N}}{\mathrm{N}_{\mathrm{ref}}}\right)^{\beta}
$$

Where:

$\gamma=5=$ A constant representing two intersecting straight lines which can be replaced by a single curve

$\alpha, \beta=$ Material dependent parameters that must be experimentally determined (typically taken as 0.25 and 0.4 , respectively)

Notice the linear damage accumulation at lower life ratios and curvilinear damage accumulation at higher life ratios.

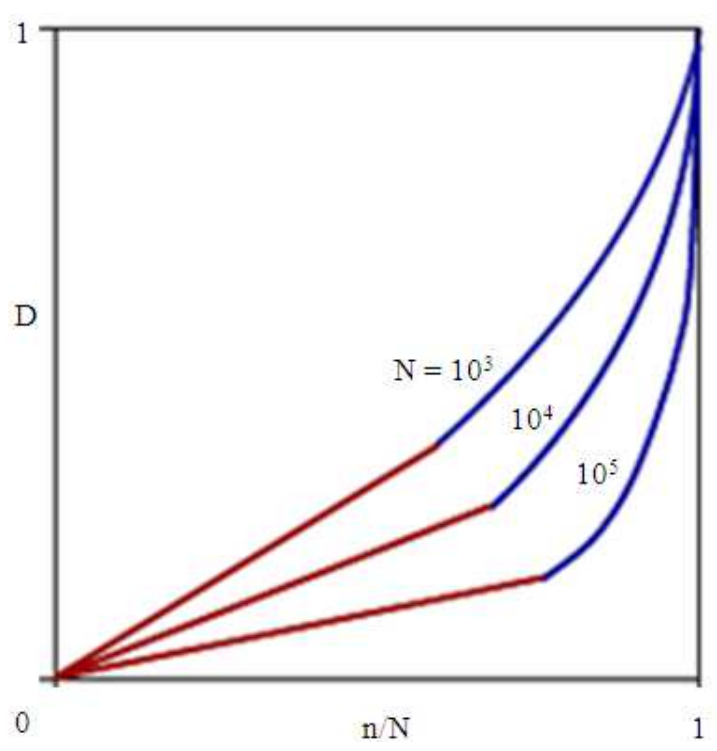

Fig. 3. Double damage curve approach

\subsection{Fatigue: State of the Art}

The fatigue crack growth prediction models are fracture mechanics based models that have been developed to support the damage tolerance concepts in metallic structure. During the last decades numerous papers have been published on fatigue life and fatigue crack growth prediction under constant and variable amplitude loading. A thorough examination of literature provides an overview of prediction models for crack growth as a scientific and engineering knowledge about fatigue of material and structures, which includes fatigue life prediction models. The prediction models are categorized according to the type of loading and the concept of each model is described. In the 1950s, many investigators mentioned (Beden et al., 2009) how early in the fatigue life they could observe micro-cracks (Fig. 4). Since then it was clear that the fatigue life under cyclic loading consisted of two phases, the crack initiation life followed by a crack growth period until failure.

The crack initiation period may cover a large percentage of the fatigue life under high-cycle fatigue, i.e. under stress amplitudes just above the fatigue limit. But for larger stress amplitudes the crack growth period can be a substantial portion of the fatigue life. The question is how to define the transition from the initiation period to the crack growth period. The stress intensity factor was introduced for the correlation between the crack growth rate, $\mathrm{da} / \mathrm{dN}$ and the stress intensity factor range, $\Delta \mathrm{K}$. 


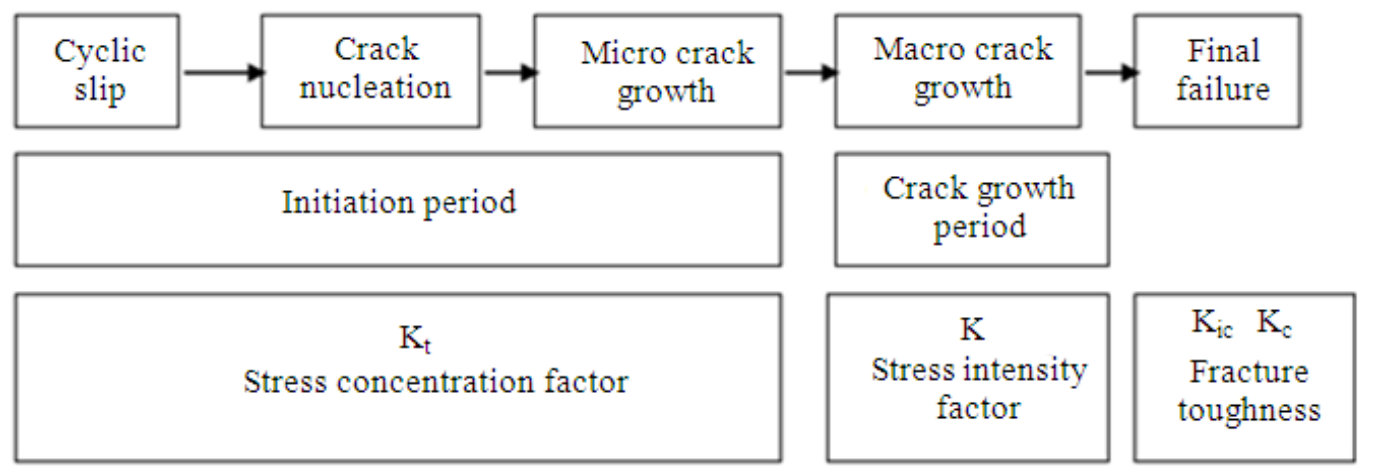

Fig. 4. Different phases of the fatigue life and relevant factors

The results of the crack growth tests of Paris (1961) show a linear relation between $\log (\mathrm{da} / \mathrm{dN})$ and $\log (\Delta \mathrm{K})$ as follows Equation 4:

$$
\frac{\mathrm{da}}{\mathrm{dN}}=\mathrm{C}(\Delta \mathrm{K})^{\mathrm{m}}
$$

with $\mathrm{C}$ and $\mathrm{m}$ as experimentally obtained constants.

Although the fatigue crack growth is subjected to physical laws, the main disadvantage is that its model parameters have no physical significance. There is a very large number of fatigue crack growth models but only promising and/or commonly used models are discussed.

The fatigue crack growth models commonly used for constant amplitude loading are the simplest to perform because no load history has to be considered. There exist various models like (Beden et al., 2009): Paris model, Walker model, Forman model, Collipriest model, McEvily model, Frost and Pook model, Zheng model, Wang model, Miller and Gallagher models.

Each of these models varied in the approach used, number of calibration and complexity. The fact that all used different fatigue growth models reconfirms the fact that there is no standard methodology used to perform the fatigue growth life predictions for structure under random loading. But there is a trend for un-conservative models for crack lives exceeding $10^{5}$ cycles and excellent prediction model results for crack lives below $10^{5}$ cycles.

The Paris model is a simple and well known predicting model of fatigue crack propagation described by Paris (1963) known as the Paris law. It represents the first application of fracture mechanics to fatigue and is given by relationship (Equation 4). It is simple to use, requires two parameters which are easily obtained and is commonly used.
On the other side, the Paris law does not consider the effect of stress ratio and it depends upon the material used. For steel tested at various stress ratios, a family of parallel straight lines is produced. This means that the value of $\mathrm{m}$ is the same for all stress ratios but the value of $\mathrm{C}$ is specific for a particular stress ratio.

\subsection{Damage Evolution Law}

The fatigue of materials under cyclic loading and the micro-cracks (starting from $\alpha_{0}$ ) that become detectable and unstable (Fig. 5), will make the macro-cracks grow to a critical length $\left(a=a_{C}\right)$ creating thus fractures and hence leading to failure (Fig. 6).

The Paris law (Bartelmus and Zimroz, 2009; Ahmad-Shariff, 2007) given by (Equation 4), where:

$$
\begin{aligned}
& \frac{\mathrm{da}}{\mathrm{dN}} \quad=\text { The increase of the crack per } \\
& \text { cycle } \\
& \Delta \mathrm{K}(\mathrm{a})=\mathrm{Y}(\mathrm{a}) \Delta \sigma \sqrt{\pi \mathrm{a}}=\text { The stress intensity factor } \\
& \mathrm{Y} \text { (a) } \quad=\text { The function of the } \\
& \text { component's crack geometry. } \\
& \Delta \sigma \quad=\text { The range of the applied stress } \\
& \mathrm{C} \text { and } \mathrm{m} \quad=\text { Constants of materials; } \\
& (0<\mathrm{C}<<1) ;(2 \leq \mathrm{m} \leq 4)
\end{aligned}
$$

\subsection{Nonlinear Cumulative Damage Modeling 1.8.1. Sensory Data Needed for Prognostic Study}

To study the prognosis of a degraded component, our idea is to predict and estimate the end of life of the component by tracking and modeling the degradation function. Our damage model, whose evolution up to the point of macro-crack initiation, is represented in Fig. 7. 


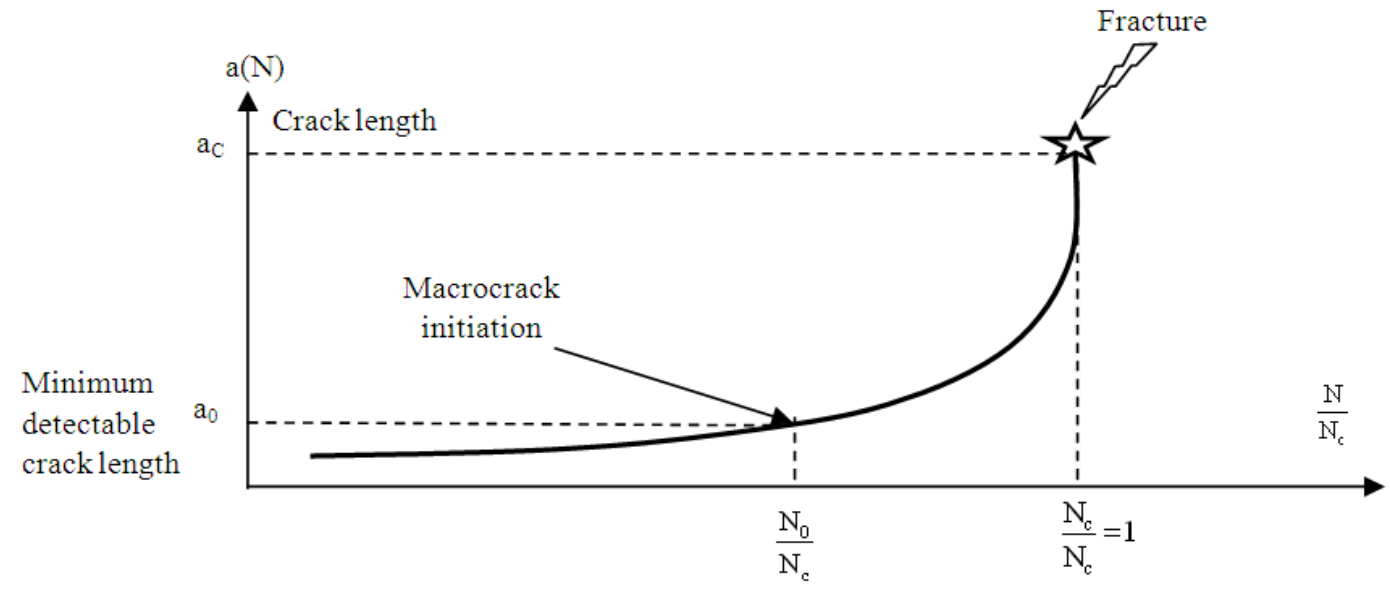

Fig. 5. Pre-Crack fatigue damage

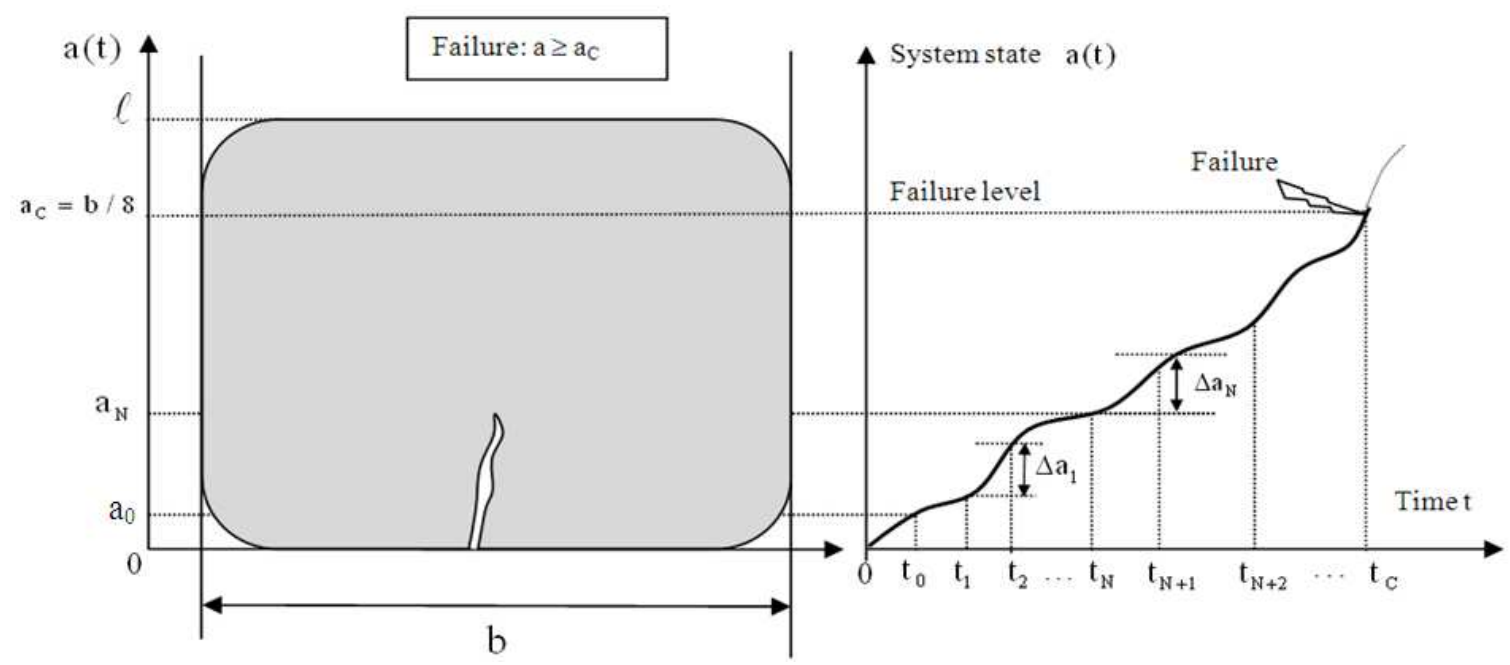

Fig. 6. Crack length evolution

The fatigue of material under repeated stresses is represented by the WOhler curve (Schutz, 1996) (Fig. 8).

The initial detectable crack $\alpha_{0}$ (Fig. 6) is measured by a sensor and its value is incorporated in the damage prognostic model through the initial damage given by the following expression:

$$
\mathrm{D}_{0}=\frac{\mathrm{a}_{0}}{\mathrm{a}_{\mathrm{C}}-\mathrm{a}_{0}}
$$

To facilitate the analysis, it is convenient to adopt a damage measurement $\mathrm{D} \in[0,1]$ by using the nonlinear cumulative damage law. The state of damage in a specimen at a particular cycle during fatigue is represented by a scalar damage function $D(N)$. The magnitude $\mathrm{D}=0$ corresponds to no damage and $\mathrm{D}=1$ corresponds to the appearance of the first macro-crack (total damage).

The following model represents the non linear evolution of damage D in term of the number of cycle $\mathrm{N}$ given under the following differential Equation 5 (Kulkarni et al., 2006):

$$
\frac{\mathrm{dD}}{\mathrm{dN}}= \begin{cases}\frac{1}{\mathrm{~N}_{\mathrm{C}}}\left(1-\frac{\sigma_{0}}{\Delta \sigma / 2}\right)^{\mathrm{m}} \frac{1}{(1-\mathrm{D})^{\alpha}} & \text { if } \Delta \sigma / 2>\sigma_{0} \\ 0 & \text { if } \Delta \sigma / 2<\sigma_{0}\end{cases}
$$




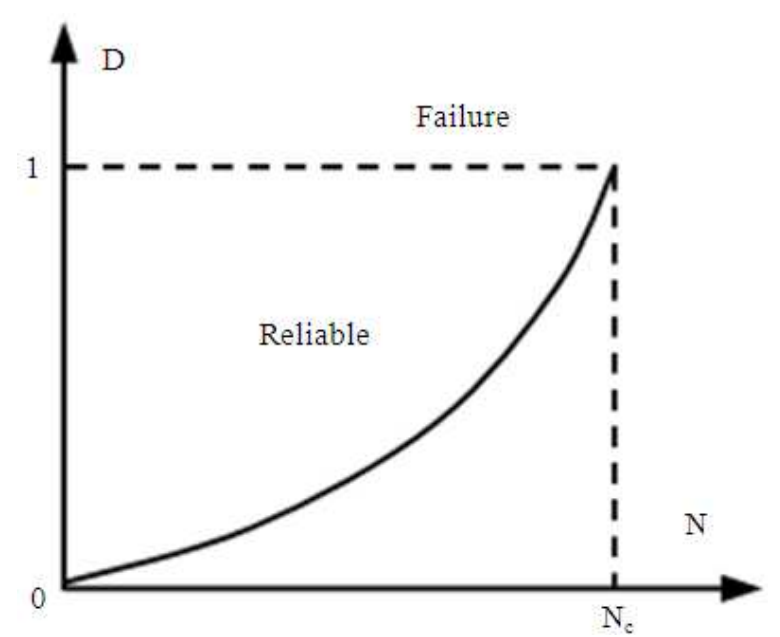

Fig. 7. Nonlinear law of damage

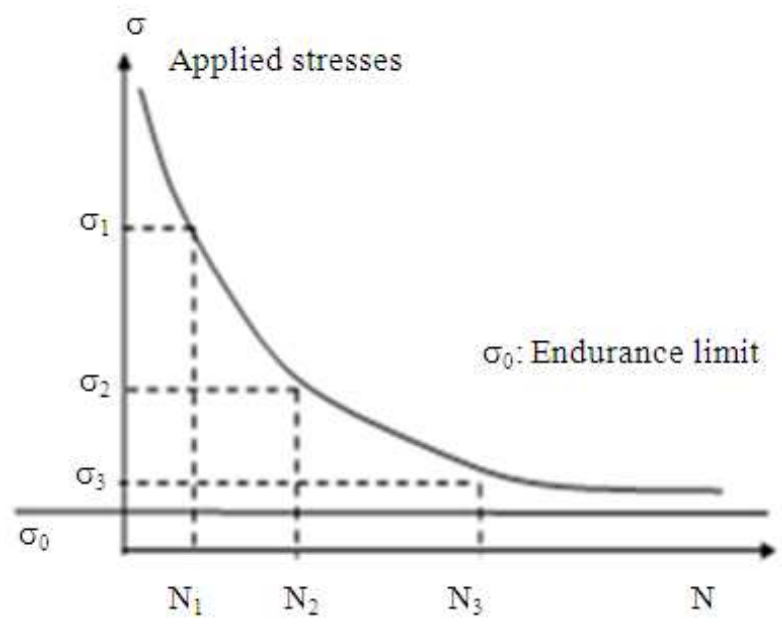

Fig. 8. WOhler curve

Where:

$\mathrm{N}_{\mathrm{C}}=$ Number of cycles at failure as a normalizing constant

$\Delta \sigma=$ Stress range in a cycle

$\sigma_{0}=$ Endurance limit, function of the mean stress in a cycle Equation 6:

$\bar{\sigma}\left(\sigma_{0}<\Delta \sigma / 2\right)$

$\sigma_{0}(\bar{\sigma})=\sigma_{0}(0)\left(1-\frac{\bar{\sigma}}{\sigma_{\text {ult }}}\right)$

Where:

$\sigma_{\text {ult }}=$ Ultimate tensile strength of the material $\mathrm{m}$ and $\alpha=$ Constants depending on the material and loading condition $(\mathrm{m} \approx 2.91$ and $\alpha \approx 2.23)$

\subsection{Solution of the Differential Equation of Degradation}

The resolution of the following differential equation is presented as follows Equation 7:

$$
\begin{aligned}
& \frac{d \mathrm{D}}{\mathrm{dN}}= \begin{cases}\frac{1}{\mathrm{~N}_{\mathrm{C}}}\left(1-\frac{\sigma_{0}}{\Delta \sigma / 2}\right)^{\mathrm{m}} \frac{1}{(1-\mathrm{D})^{\alpha}} & \text { if } \Delta \sigma / 2>\sigma_{0} \\
0 \quad & \text { if } \Delta \sigma / 2<\sigma_{0}\end{cases} \\
& \Rightarrow \int_{\mathrm{D}_{0}}^{\mathrm{D}_{\mathrm{N}}}(1-\mathrm{D})^{\alpha} \mathrm{dD}=\int_{\mathrm{N}_{0}}^{\mathrm{N}} \frac{1}{\mathrm{~N}_{\mathrm{C}}}\left(1-\frac{\sigma_{0}}{\Delta \sigma / 2}\right)^{\mathrm{m}} \mathrm{dN} \\
& \Rightarrow \mathrm{D}(\mathrm{N})=1-\left[\left(1-\mathrm{D}_{0}\right)^{\alpha+1}-\frac{\mathrm{N}-\mathrm{N}_{0}}{\mathrm{~N}_{\mathrm{C}}}\left(1-\frac{\sigma_{0}}{\Delta \sigma / 2}\right)^{\mathrm{m}}(\alpha+1)\right]^{\frac{1}{\alpha+1}}
\end{aligned}
$$

where, $\mathrm{D}\left(\mathrm{N}_{0}\right)=\mathrm{D}_{0}$ : damage at $\mathrm{N}=\mathrm{N}_{0}$ cycles corresponding to an initial crack length $\mathrm{a}_{0}$.

We choose an equivalent damage parameter, to be measured by structural health monitoring. The plotting of the previous expression of $\mathrm{D}(\mathrm{N})$ is presented in Fig. 9.

As a particular case, take Equation 8:

$$
\begin{aligned}
& \mathrm{D}_{0}=0 \text { for } \mathrm{N}=\mathrm{N}_{0} \text { and } \mathrm{D}_{\mathrm{C}}\left(\mathrm{N}_{\mathrm{C}}\right)=1 \\
& \Rightarrow \mathrm{D}(\mathrm{N})=1-\left[1-\left(\frac{\mathrm{N}-\mathrm{N}_{0}}{\mathrm{~N}_{\mathrm{C}}}\right)\left(1-\frac{\sigma_{0}}{\bar{\sigma}}\right)^{\mathrm{m}}(\alpha+1)\right]^{\frac{1}{\alpha+1}}
\end{aligned}
$$

For the failure case: $\left(\mathrm{N}=\mathrm{N}_{\mathrm{C}}\right)$, it follows that:

$$
\begin{aligned}
& 1=1-\left[1-\left(\frac{\mathrm{N}_{\mathrm{C}}-\mathrm{N}_{0}}{\mathrm{~N}_{\mathrm{C}}}\right)\left(1-\frac{\sigma_{0}}{\bar{\sigma}}\right)^{\mathrm{m}}(\alpha+1)\right]^{\frac{1}{\alpha+1}} \\
& \Rightarrow\left(\frac{\mathrm{N}_{\mathrm{C}}-\mathrm{N}_{0}}{\mathrm{~N}_{\mathrm{C}}}\right)\left(1-\frac{\sigma_{0}}{\bar{\sigma}}\right)^{\mathrm{m}}=\frac{1}{\alpha+1} \\
& \text { Assume that } \mathrm{N}_{0}=0 \Rightarrow\left(1-\frac{\sigma_{0}}{\bar{\sigma}}\right)^{\mathrm{m}}=\frac{1}{\alpha+1} \\
& \Rightarrow 1-\frac{\sigma_{0}}{\bar{\sigma}}=\frac{1}{(\alpha+1)^{\frac{1}{\mathrm{~m}}}}
\end{aligned}
$$

Therefore Equation 9:

$$
\sigma_{0}=\bar{\sigma}\left(1-\frac{1}{(\alpha+1)^{\frac{1}{m}}}\right)
$$




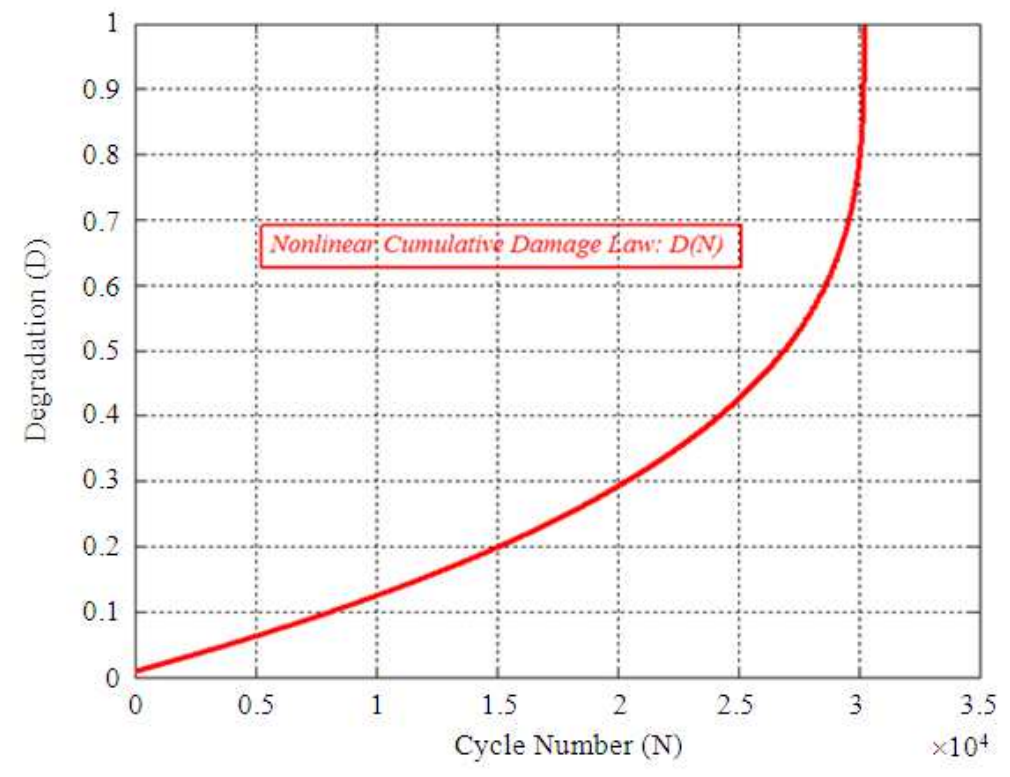

Fig. 9. Nonlinear $\mathrm{D}(\mathrm{N})$ curve

\subsection{Relation between $D$ and $N$ at a Specific Cycle $\mathbf{N}_{1}$}

Let us study the relation between the degradation $\mathrm{D}$ and the cycle of stress $\mathrm{N}$, to do that easily, let us integrate the relation of degradation between cycle 1 and cycle 2 assuming that the failure occurs at cycle 2 Equation 10 :

$$
\begin{aligned}
& (1-\mathrm{D})^{\alpha} \mathrm{dD}=\frac{1}{\mathrm{~N}_{\mathrm{C}}}\left(1-\frac{\sigma_{0}}{\Delta \sigma / 2}\right)^{\mathrm{m}} \mathrm{dN} \\
& \Rightarrow \int_{\mathrm{D}_{1}}^{\mathrm{D}_{\mathrm{C}}=1}(1-\mathrm{D})^{\alpha} \mathrm{dD}=\int_{\mathrm{N}_{1}}^{\mathrm{N}_{\mathrm{C}}} \frac{1}{\mathrm{~N}_{\mathrm{C}}}\left(1-\frac{\sigma_{0}}{\Delta \sigma / 2}\right)^{\mathrm{m}} \mathrm{dN} \\
& \text { Then: } \quad \mathrm{D}_{1}\left(\mathrm{~N}_{1}\right)=1-\left[(\alpha+1)\left(1-\frac{\mathrm{N}_{1}}{\mathrm{~N}_{\mathrm{C}}}\right)\left(1-\frac{\sigma_{0}}{\Delta \sigma / 2}\right)^{\mathrm{m}}\right]^{\frac{1}{\alpha+1}}
\end{aligned}
$$

\subsection{Recursive Relation of Nonlinear Damage D}

To construct a recurrent relation for the sequence of $\mathrm{D}$, we proceed as follows:

$$
\begin{aligned}
& (1-\mathrm{D})^{\alpha} \mathrm{dD}=\frac{1}{\mathrm{~N}_{\mathrm{C}}}\left(1-\frac{\sigma_{0}}{\Delta \sigma / 2}\right)^{\mathrm{m}} \mathrm{dN} \\
& \Rightarrow \int_{\mathrm{D}_{\mathrm{i}}}^{\mathrm{D}_{\mathrm{i}+1}}(1-\mathrm{D})^{\alpha} \mathrm{dD}=\int_{\mathrm{N}_{\mathrm{i}}}^{\mathrm{N}_{\mathrm{i}+1}} \frac{1}{\mathrm{~N}_{\mathrm{C}}}\left(1-\frac{\sigma_{0}}{\bar{\sigma}}\right)^{\mathrm{m}} \mathrm{dN} ; \bar{\sigma}=\Delta \sigma / 2
\end{aligned}
$$$$
\text { where } \mathrm{N}_{\mathrm{i}+1}-\mathrm{N}_{\mathrm{i}}=1 \text { cycle. }
$$

Hence, our prognostic model in nonlinear case is given by Equation 11:

$$
\mathrm{D}_{\mathrm{i}+1}=1-\left[\left(1-\mathrm{D}_{\mathrm{i}}\right)^{\alpha+1}-\frac{(\alpha+1)}{\mathrm{N}_{\mathrm{C}}}\left(1-\frac{\sigma_{0}}{\bar{\sigma}}\right)^{\mathrm{m}}\right]^{\frac{1}{\alpha+1}}
$$

The previous recursive relation leads to a sequence of values $D_{i}$ whose limit is 1 :

$$
\mathrm{D}_{0}, \mathrm{D}_{1}, \mathrm{D}_{2}, \cdots \cdots, \mathrm{D}_{\mathrm{i}}, \mathrm{D}_{\mathrm{i}+1}, \cdots \cdots, \mathrm{D}_{\mathrm{C}}=1
$$

And as the stress-load is expressed in terms of time ( $t$ ), then we can plot the curve of degradation $\mathrm{D}$ in function of time $(\mathrm{t})$.

\subsection{Application to a Vehicle Suspension System}

To illustrate the proposed nonlinear analytic approach, it will be applied to important mechanical systems which are the suspensions in automotive industry. The failure of this device is among the main causes of vehicles breakdown. The prognostic studies in this field are essential for the automotive industries. The fatigue is at the origin of most suspensions failure; therefore, their prognostic is crucial to enhance the vehicle lifetime. Our proposed model, based on the nonlinear accumulation of degradation due to fatigue, can very well be applied to this case since the suspension dampers are subject to crack fatigue that propagates and reaches the critical level. 


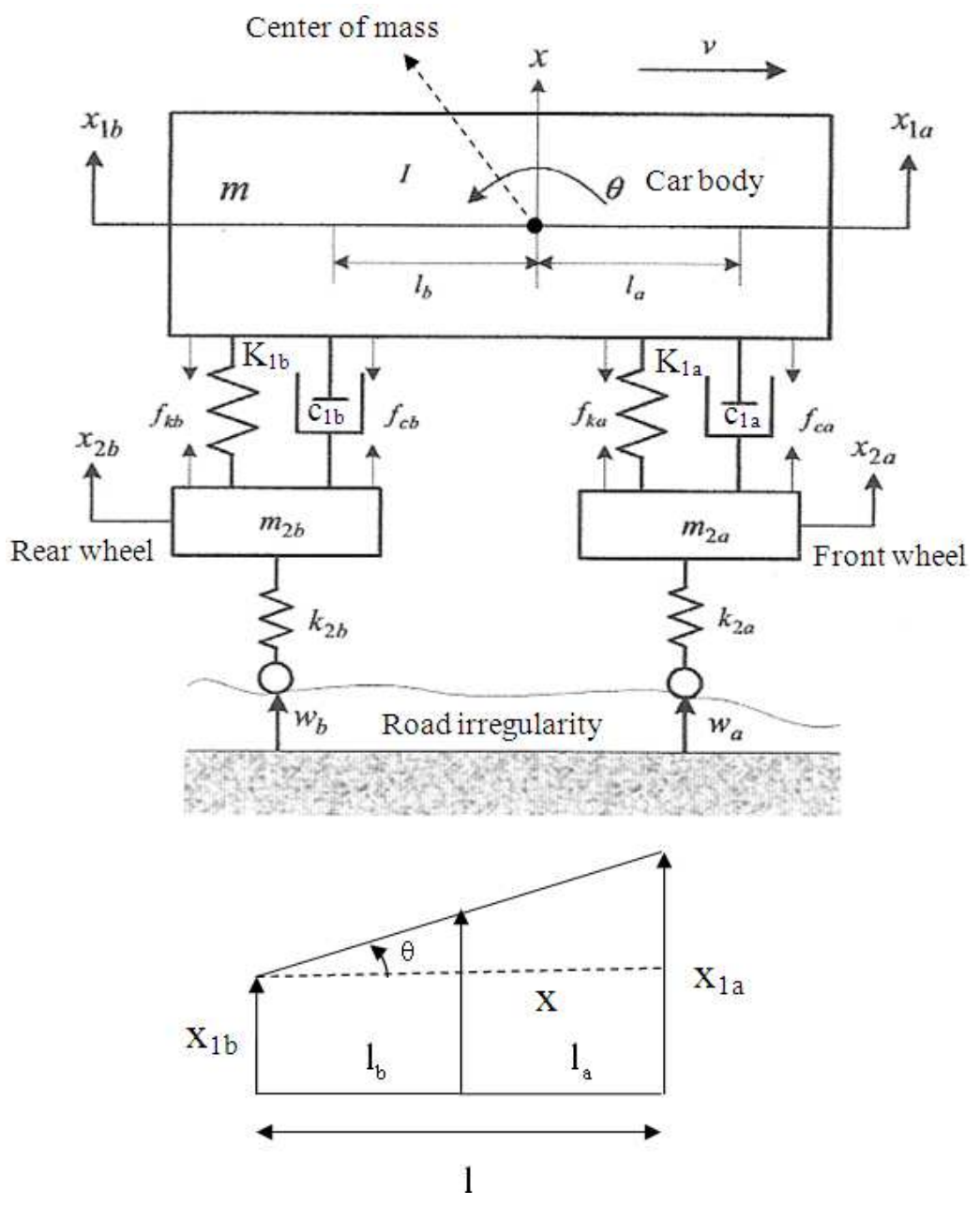

Fig. 10. Vehicle suspension model

Let us consider a half-vehicle suspension system (Fig. 10) subject to non-regular road surface excitations (Qiu et al., 2002).

The dynamic matrix equation of the model is given by Equation 12:

$$
\mathrm{M} \ddot{z}+\mathrm{Nż}+\mathrm{Kz}=\mathrm{Eu}
$$

Where:

$\mathrm{M}=$ Matrix function of $\mathrm{m}, \mathrm{l}_{\mathrm{a}}, \mathrm{l}_{\mathrm{b}}, \mathrm{m}_{2 \mathrm{a}}$ and $\mathrm{m}_{2 \mathrm{~b}}$

$\mathrm{N}=$ Matrix function of $\mathrm{l}_{\mathrm{a}}, \mathrm{l}_{\mathrm{b}}, \mathrm{c}_{\mathrm{a}}$ and $\mathrm{c}_{\mathrm{b}}$

$\mathrm{K}=$ Matrix function of $\mathrm{l}_{\mathrm{a}}, \mathrm{l}_{\mathrm{b}}, \mathrm{k}_{1 \mathrm{a}}, \mathrm{k}_{2 \mathrm{a}}, \mathrm{k}_{1 \mathrm{~b}}$ and $\mathrm{k}_{2 \mathrm{~b}}$

$\mathrm{E}=$ Matrix function of $\mathrm{k}_{2 \mathrm{a}}$ and $\mathrm{k}_{2 \mathrm{~b}}$

\subsection{System Identification}

The model parameters are:
$\mathrm{m}=$ Vehicle mass
I $\quad=$ moment of inertia
$\mathrm{m}_{2 \alpha} \quad=$ Mass of front wheel
$\mathrm{m}_{2 \mathrm{~b}} \quad=$ Mass of rear wheel
$\theta \quad=$ Rotary angle of vehicle
$\mathrm{x}=$ Vertical displacement
$\mathrm{c}_{\mathrm{i}} \quad=$ Friction coefficient of damping $(\mathrm{i}=\mathrm{a}, \mathrm{b})$
$\mathrm{f}_{\mathrm{ca}}, \mathrm{f}_{\mathrm{cb}}=$ Damping force of the front/rear wheel
$\mathrm{f}_{\mathrm{ka}}, \mathrm{f}_{\mathrm{kb}}=$ Restoring force of the front/rear wheel
$\mathrm{k}_{1 \mathrm{a}}, \mathrm{k}_{1 \mathrm{~b}}=$ Spring constants of the front/rear suspension
$\mathrm{k}_{2 \mathrm{a}}, \mathrm{k}_{2 \mathrm{~b}}=$ Spring constants of the front/rear wheel
$\mathrm{x}_{2 \mathrm{a}}, \mathrm{x}_{2 \mathrm{~b}}=$ Vertical displacement of the front/rear wheel
$\mathrm{x}_{1 \mathrm{a}}, \mathrm{x}_{1 \mathrm{~b}}=$ Displacement of the vehicle body at front/rear
$\mathrm{l}_{\mathrm{a}}, \mathrm{l}_{\mathrm{b}}=$ Distance of the front/rear suspension to center
$\mathrm{w}_{\mathrm{a}}, \mathrm{w}_{\mathrm{b}}=$ Irregular excitations from the road surface 


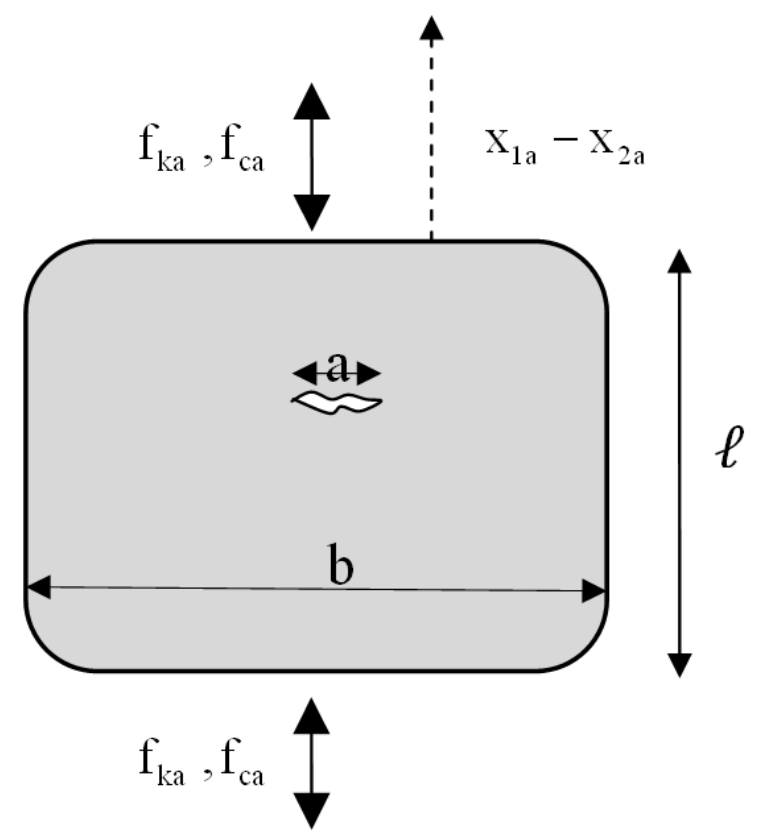

Fig. 11. Suspension fatigue crack modeling

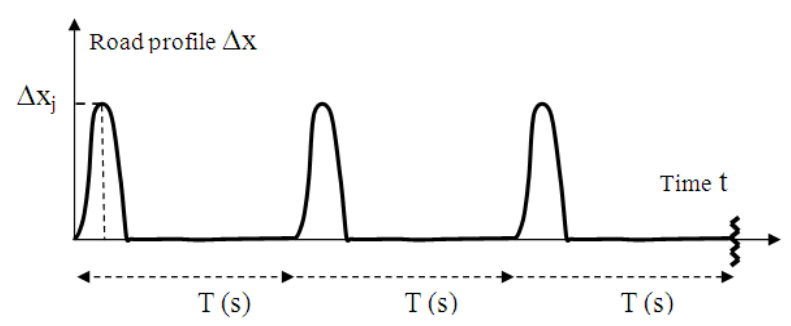

Fig. 12. Simulated road profile

The input excitation vector is: $\mathrm{u}=\left[\begin{array}{ll}\mathrm{w}_{\mathrm{a}} & \mathrm{w}_{\mathrm{b}}\end{array}\right]^{\mathrm{T}}$.

The output damper displacement vector is:

$$
\mathrm{Z}=\left[\begin{array}{llll}
\mathrm{X}_{1 \mathrm{a}} & \mathrm{X}_{2 \mathrm{a}} & \mathrm{x}_{1 \mathrm{~b}} & \mathrm{x}_{2 \mathrm{~b}}
\end{array}\right]^{\mathrm{T}}
$$

\subsection{Fatigue Damage Modeling of Suspension}

Assume that the front suspension of the system has a crack perpendicular to the exterior load (Fig. 11).

Suppose that the maximum of a is:

$a_{C}=b / 8$

Where:

$\mathrm{a}=$ The crack length

$\mathrm{b}=$ The width of the suspension device
Table 1. Characteristics of each mode of roads

\begin{tabular}{ll}
\hline Road mode & $\Delta \mathrm{x}_{\mathrm{j}}(\mathrm{mm})$ \\
\hline Severe (mode 1) & 100 \\
Fair (mode 2) & 50 \\
Good (mode 3) & 25 \\
\hline
\end{tabular}

The degradation model is simulated by generating the road profile $u_{j}=\left[\begin{array}{ll}w_{a} & w_{b}\end{array}\right]_{j}^{T}$ (Cempel, 1987) for the 3 modes of roads (Table $\mathbf{1}$ ).

For each simulation, the solution of system of matrices (Equation 12) gives the output vector $z_{j}$. Then, the range of suspension displacement is given, for front wheel, by Equation 13:

$\Delta \mathrm{x}_{\mathrm{j}}=\mathrm{x}_{\mathrm{1a}}^{\mathrm{j}}-\mathrm{x}_{2 \mathrm{a}}^{\mathrm{j}}$

The amplitude of stresses developed in suspension due to $\Delta \mathrm{x}_{\mathrm{j}}$ is given by Equation 14 :

$\Delta \sigma_{\mathrm{j}}=\mathrm{E} \times \frac{\Delta \mathrm{x}_{\mathrm{j}}}{\ell}$

Where:

$\ell=$ The length of the suspension device $(\ell=500$ $\mathrm{mm})$

$\Delta \mathrm{x}_{\mathrm{j}}=$ The variation of this length (dilation) due to road profile excitation

$\mathrm{E}=$ Young's modulus of suspension material (200 $\mathrm{GPa})$

\subsection{Simulation of Three Road Profiles}

To take into account various state of roads, we consider three different types of roads which are: severe, fair and good. In the following table (Table 1), we indicate the characteristics of each type of roads.

We consider the parabolic road profile for period $\mathrm{T}$ in seconds of vehicle circulation time as a recurrent interval and we repeat this interval as needed until reaching the failure $(D=1)$. The model resulting is drawn in Fig. 12.

Each interval shows that the road profile contains a curve with a peak value followed by a horizontal run of zero amplitude. The following parameters are considered in the simulation (Kulkarni et al., 2006):

$$
\begin{array}{ll}
\mathrm{N}_{\mathrm{C}} & =\begin{array}{l}
\text { Normalizing constant taken to be equal to } \\
\text { the number of cycles at failure }\left(\mathrm{N}_{\mathrm{C}}=10^{5}\right)
\end{array} \\
\alpha & = \\
\mathrm{m} & =2.91
\end{array}
$$




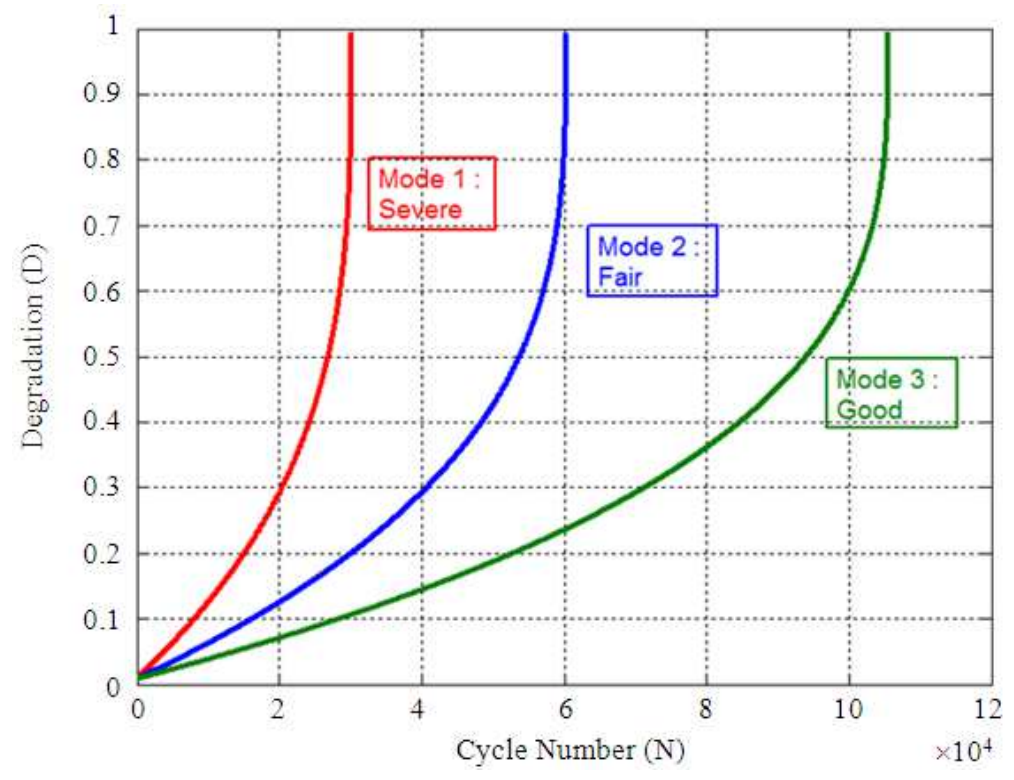

Fig. 13. Suspension degradation under nonlinear law for three modes of road excitation

$$
\begin{aligned}
\bar{\sigma}=\Delta \sigma / 2= & \text { Stress amplitude in one cycle, this } \\
& \text { parameter is generated as input load, } \\
& \text { whose mean is taken to be equal to } 280 \\
& \text { MPa } \\
= & \text { The fatigue limit (endurance limit of } \\
& \text { material) taken equal to } 180 \mathrm{MPa}
\end{aligned}
$$

\subsection{RUL Computation}

The main goal in a prognostic study is, as previously indicated, the evaluation of the remaining useful lifetime of the system. The RUL can be deduced from the damage curve $\mathrm{D}(\mathrm{N})$ since it is its complement. Then, at each cycle $\mathrm{N}$, the length from cycle $\mathrm{N}$ to the critical cycle $\mathrm{N}_{\mathrm{C}}$ corresponding to the threshold $\mathrm{D}=1$, is the required RUL. The entire RUL is deduced from the expression:

$$
\mathrm{N}_{\mathrm{C}}-\mathrm{N}_{0}
$$

Where:

$\mathrm{N}_{\mathrm{C}}=$ The necessary cycle number to reach failure (appearance of the first macro-cracks)

$\mathrm{N}_{0}=$ The initial cycle number taken generally equal to 0

\subsection{Results of Simulation}

From the simulation results (Equation 11) we can represent in Fig. 13 and 14 the evolution of the degradation D and of the RUL for the suspension under the 3 modes of roads with the profile properties indicated in Table 1.

The number of cycles to failure for each mode is: 30,159 cycles for mode $1,60,318$ cycles for mode 2 and 105,560 cycles for mode 3 .

These curves decrease from total lifetime of the device to zero where $\mathrm{D}=1$. From these curves we can deduce at each instant the RUL of the device and hence the prognostic result can be inferred.

The conversion of RUL from cycles to seconds gives the following values: $1.2 \times 10^{5}$ (s) for mode 1 , $2.4 \times 10^{5}(\mathrm{~s})$ for mode 2 and $11.1 \times 10^{5}(\mathrm{~s})$ for mode 3 .

Referring to the references (Sankavaram et al., 2009; Wren, 2006; Rahman, 2010; Luo et al., 2003), the validation of the present results cannot be explained without taking into consideration the nonlinear basis of the current study contrary to the linear damage model adopted in the previous references. Therefore, the results got here are realistic when compared to those obtained by the works of these authors.

\subsection{Comparison with the Linear Case (Abou Jaoude et al., 2010)}

We can deduce from Fig. 14 and 15 that first of all the nonlinear case of damage is more optimistic than the linear case concerning the lifetime because the values are at least 10 times larger. 


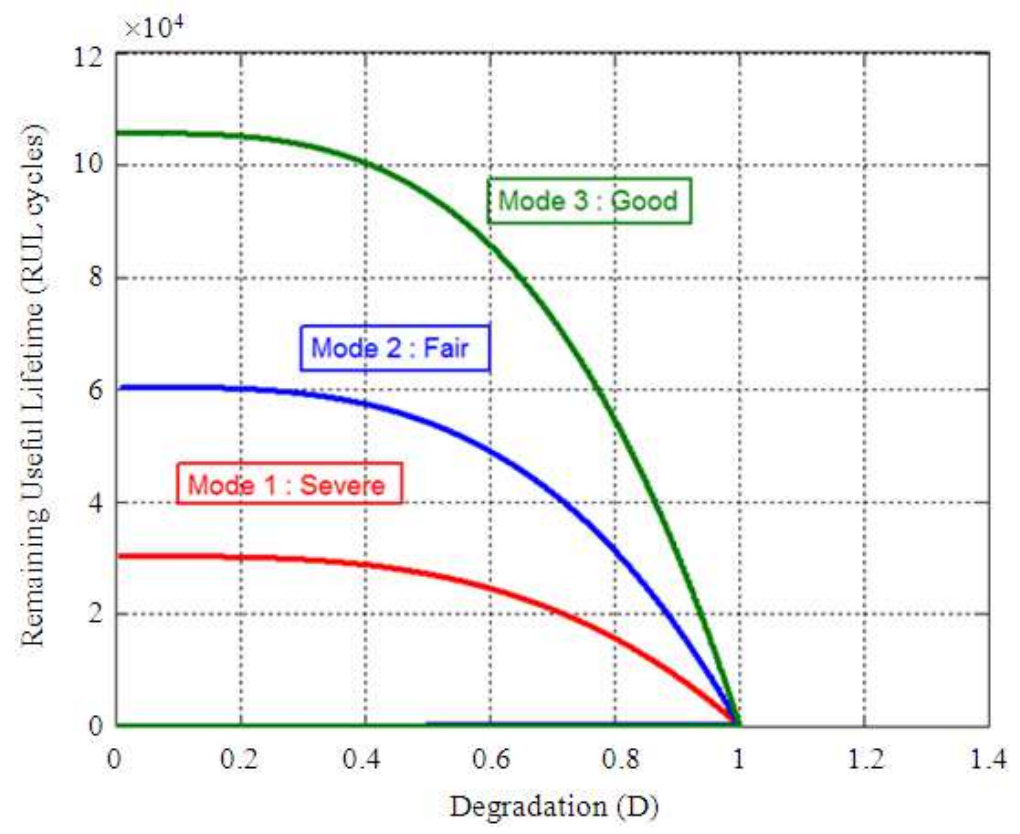

Fig. 14. Nonlinear case

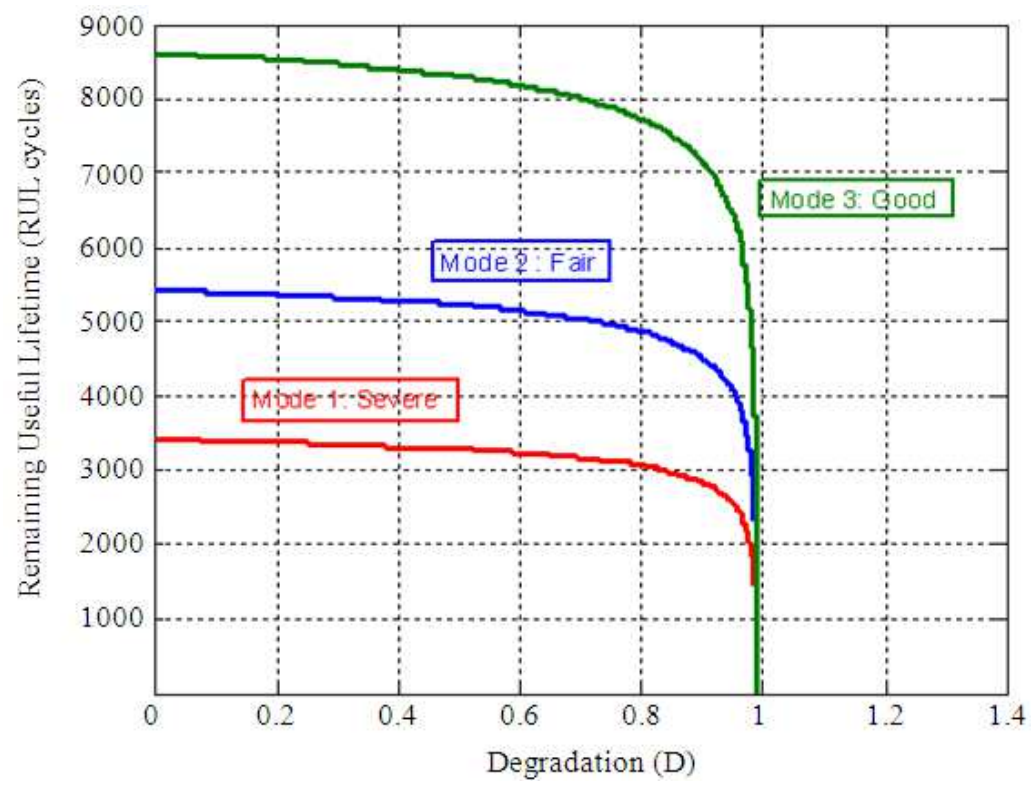

Fig. 15. Linear case

Secondly, the decreasing of RUL in nonlinear case is less steep at the end than the linear case because the nonlinear curves reach the zero value progressively. Finally, we can remark that near the failure zone where $\mathrm{D}=1$ the nonlinear study seems to give here more logical and realistic damage behavior for the different road profiles than the linear case. In fact, between good and severe profiles, the nonlinear case makes the difference when approaching failure limit whereas the linear case does not. 


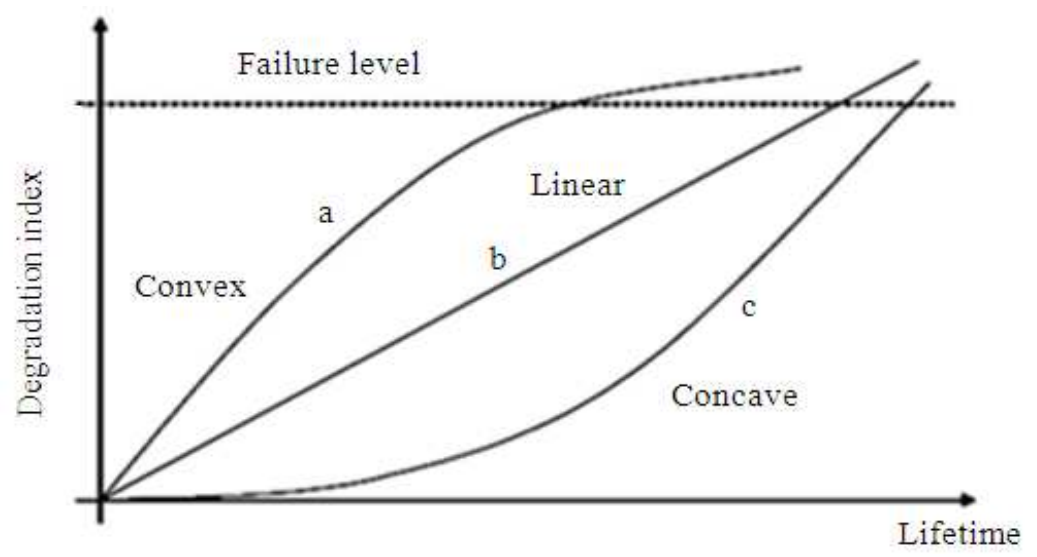

Fig. 16. Different degradation trends

The optimistic results obtained from nonlinear case can be explained by the fact that when the real nonlinear trends of degradation are of concave form then the damage accumulation is overestimated when using a linear form, whereas when it is really convex, the damage accumulation is underestimated when using a linear form (Fig. 16).

\subsection{Advantages of the Proposed Model}

In comparison with predictive RUL models available in literature (Beden et al., 2009), the advantages of the present model are:

- It is simple and practical in application to various industrial systems for fatigue life prediction

- The fact of using a nonlinear law, if it exists, for damage accumulation, makes it more efficient and realistic in predicting the remaining useful lifetime

- When multiple load levels are simultaneously considered, the linear law of damages accumulation like Miner's law leads to inaccuracy (Goodin et al., 2007) in life prediction whereas the nonlinear law of damage permits to consider the effect mentioned above

- It takes into account the load interaction effects between high-cycle and low-cycle loadings contrary to predictive models based on linear damage law

- Its efficiency relatively to other models has been often more pronounced under multi-axial loading, particularly when the loading is non-proportional

- It considers the influent environment that can accentuate the nonlinear aspect related to some materials behavior subject to fatigue effects (brittle materials for example)

- The Paris law of fatigue for crack growth adopted in the present model is simple to use and requires two parameters easily obtained. It is the simplest to perform because no load history has to be considered. it allows an excellent prediction model results for crack lives below $10^{5}$ cycles

\section{CONCLUSION}

A prognostic model is proposed in this work based on nonlinear accumulation of damage due to fatigue crack propagation. The damage state of the device is measured by a degradation indicator in terms of the number of cycles. Moreover, the model is expressed by a recursive nonlinear function relating the degradation in two consecutive cycles to the critical number of cycles and the endurance stress limit of the material. To show the efficiency of this prognostic model, it is applied to predict the fatigue life of a vehicle suspension system. The RUL results obtained are compared to previous results of a linear model and the differences are justified by the multiple trends of degradation. The present nonlinear prognostic model will allow us to include the stochastic aspect as a prospective work, which will improve the intended prediction capacity.

\section{REFERENCES}

Abou Jaoude, A.A., K. El-Tawil, S. Kadry, H. Noura and M. Ouladsine, 2010. Analytic prognostic model for a dynamic system. Int. Rev. Automatic Control. 
Ahmad-Shariff, A., 2007. Simulation of paris-erdogan crack propagation model: The effect of deterministic harmonic varying stress range on the behaviour of damage and lifetime of structure. Proceedings of the 9th Islamic Countries Conference on Statistical Sciences, (ICCSS’ 07), pp: 12-14.

Bartelmus, W. and R. Zimroz, 2009. Vibration condition monitoring of planetary gearbox under varying external load. Mech. Syst. Signal Process., 23: 246257. DOI: 10.1016/j.ymssp.2008.03.016

Beden, S.M., S. Abdullah and A.K. Ariffin, 2009. Review of fatigue crack propagation models for metallic components. Eur. J. Sci. Res., 28: 364-397.

Byington, C.S., M.J. Roemer and T. Galie, 2002. Prognostic enhancements to diagnostic systems for improved condition-based maintenance. Proceedings of the IEEE Aerospace Conference, (AC' 02), IEEE Xplore Press, pp: 6-2815-6-2824. DOI: 10.1109/AERO.2002.1036120

Cempel, C., 1987. Simple condition forecasting techniques in vibroacoustical diagnostics. Mech. Syst. Signal Process., 1: 75-82. DOI: 10.1016/08883270(87)90084-7

Goodin, E., A. Kallmeyer and P. Kurath, 2007. Evaluation of nonlinear cumulative damage models for assessing $\mathrm{HCF} / \mathrm{LCF}$ interactions in multiaxial loadings. Research Report, University of Dayton Research Institute.

Inman, D.J., C.R. Farrar, V.L. Junior and V.S. Junior, 2005. Damage Prognosis: For Aerospace, Civil and Mechanical Systems. 1st Edn., John Wiley and Sons, Chichester, England, ISBN-10: 0470869070, pp: 470 .

Kulkarni, S.S., L.S.B. Moran, S. Krishnaswamy and J.D. Achenbach, 2006. A probabilistic method to predict fatigue crack initiation. Int. J. Fracture, 137: 9-17. DOI: $10.1007 / \mathrm{s} 10704-005-3074-0$

Lee, L., 2004. Smart products and service systems for ebusiness transformation. Proceedings of the 3rd Conference Francophone the Modelisation and Simulation Conception, Analyse and Gestion this Systemes Industriels, Apr. 25-27, Troyes, France.

Lewis, S.A. and T.G. Edwards, 1997. Smart sensors and system health management tools for avionics and mechanical systems. Proceedings of the 16th Digital Avionics Systems Conference, Oct. 26-30, IEEE Xplore Press, Irvine, CA. DOI: 10.1109/DASC.1997.637283
Luo, J., M. Namburu, K. Pattipati, L. Qiao and M. Kawamoto et al., 2003. Model-based prognostic techniques [maintenance applications]. Proceedings of IEEE Systems Readiness Technology Conference, Sept. 22-25, IEEE Xplore Press, pp: 330-340. DOI: 10.1109/AUTEST.2003.1243596

Manson, S.S. and G.R. Halford, 1981. Practical implementation of the double linear damage rule and damage curve approach for treating cumulative fatigue damage. Int. J. Fatigue, 17: 169-192. DOI: 10.1007/BF00053519

Manson, S.S. and G.R. Halford, 1986. Reexamination of Cumulative Fatigue Damage Analysis, an engineering Perspective. 1st Edn., National Aeronautics and Space Administration, Washington, D.C.

Manson, S.S., J.C. Freche and C.R. Ensign, 1967. Application of a Double Linear Damage rule to Cumulative Fatigue. 1st Edn., National Aeronautics and Space Administration, Washington, D.C., pp: 38.

Miner, M.A., 1945. Cumulative damage in fatigue. J. Applied Mech., 12: A159-A164.

Paris, P.C., 1961. A rational analytic theory of fatigue. Trend Eng., 13: 9-14.

Paris, P.C., 1963. A critical analysis of crack propagation laws. Trans. ASME D, 85: 528-534.

Peysson, F., 2009. Contribution au pronostic des systemes complexes, these de doctorat. Universite d'Aix-Marseille, France.

Qiu, J., C. Zhang, B.B. Seth and S.Y. Liang, 2002. Damage mechanics approach for bearing lifetime prognostics. Mech. Syst. Signal Process., 16: 817829. DOI: $10.1006 / \mathrm{mssp} .2002 .1483$

Rahman, M.M., 2010. Prediction of fatigue life on lower suspension arm subjected to variable amplitude loading. Proceedings of the National Conference in Mechanical Engineering Research and Postgraduate Studies, Dec. 3-4, UMP Pekan, Pahang, pp: 100-116.

Sankavaram, C., B. Pattipati, A. Kodali, K. Pattipati and M. Azam et al., 2009. Model-based and data-driven prognosis of automotive and electronic systems. Proceedings of the IEEE International Conference on Automation Science and Engineering, Aug. 2225, IEEE Xplore Press, Bangalore, pp: 96-101. DOI: 10.1109/COASE.2009.5234108

Schutz, W., 1996. A history of fatigue. Eng. Fracture Mech., 54: 263-300. DOI: 10.1016/00137944(95)00178-6 
Abdo Abou Jaoude and Khaled El-Tawil / American Journal of Engineering and Applied Sciences 6 (1): 42-56, 2013

Shigley, J. and C. Mischke, 1989. Mechanical Engineering Design. 5th Edn., McGraw-Hill, Inc., pp: 310 .

Vachtsevanos, G., F.L. Lewis, M. Roemer, A. Hess and B. Wu, 2006. Intelligent Fault Diagnosis and Prognosis for Engineering Systems. 1st Edn., John Wiley and Sons, Hoboken, N.J., ISBN-10: 047172999X, pp: 456.
Wren, J., 2006. Fatigue and durability testing. Prosig Noise and Vibration Measurement Blog. 